\title{
Systemic administration of choline acetyltransferase decreases blood pressure in murine hypertension
}

\author{
Andrew Stiegler ${ }^{1,2}$, Jian-Hua Li ${ }^{1}$, Vivek Shah ${ }^{1}$, Tea Tsaava ${ }^{1,2}$, Aisling Tynan ${ }^{1,2}$, Huan Yang ${ }^{1}$, Yehuda Tamari ${ }^{1,3}$, \\ Michael Brines ${ }^{1}$, Kevin J. Tracey ${ }^{1,2,4}$ and Sangeeta S. Chavan ${ }^{1,2,4^{*}}$ (])
}

\begin{abstract}
Acetylcholine (ACh) decreases blood pressure by stimulating endothelium nitric oxide-dependent vasodilation in resistance arterioles. Normal plasma contains choline acetyltransferase (ChAT) and its biosynthetic product ACh at appreciable concentrations to potentially act upon the endothelium to affect blood pressure. Recently we discovered a T-cell subset expressing ChAT $\left(T_{\text {ChAT }}\right)$, whereby genetic ablation of ChAT in these cells produces hypertension, indicating that production of $A C h$ by $T_{C h A T}$ regulates blood pressure. Accordingly, we reasoned that increasing systemic ChAT concentrations might induce vasodilation and reduce blood pressure. To evaluate this possibility, recombinant ChAT was administered intraperitoneally to mice having angiotensin Il-induced hypertension. This intervention significantly and dose-dependently decreased mean arterial pressure. ChAT-mediated attenuation of blood pressure was reversed by administration of the nitric oxide synthesis blocker L-nitro arginine methyl ester, indicating ChAT administration decreases blood pressure by stimulating nitic oxide dependent vasodilation, consistent with an effect of ACh on the endothelium. To prolong the half life of circulating ChAT, the molecule was modified by covalently attaching repeating units of polyethylene glycol (PEG), resulting in enzymatically active PEG-ChAT. Administration of PEG-ChAT to hypertensive mice decreased mean arterial pressure with a longer response duration when compared to ChAT. Together these findings suggest further studies are warranted on the role of ChAT in hypertension.
\end{abstract}

Keywords: Hypertension, Acetylcholine, Choline acetyltransferase, PEG-ChAT

\section{Background}

Approximately 100 million adults in the United States and more than 1 billion individuals worldwide have hypertension (Mozaffarian et al. 2015), which is a major risk factor for cardiovascular disease, kidney disease, stroke and cognitive impairment (Pugh et al. 2019; González et al. 2018; Zhou et al. 2018; World Health Organization 2013). Abnormalities in the renin-angiotensin system (RAS) have been implicated in a number of forms of clinically

\footnotetext{
*Correspondence: schavan@northwell.edu

${ }^{1}$ Institute of Bioelectronic Medicine, The Feinstein Institutes for Medical Research, Northwell Health, 350 Community Drive, Manhasset, NY 11030, USA

Full list of author information is available at the end of the article
}

significant elevated blood pressure, including essential hypertension (Crowley et al. 2006). Currently available therapies to treat hypertension are inadequate, because $75 \%$ of medicated hypertensive patients continue to have increased blood pressure (Whelton et al. 2017). Therefore, new therapeutic strategies for hypertension are urgently needed.

Changes in blood vessel diameter produce changes in blood pressure via active vasoconstriction or vasodilation, which is a major physiological mechanism to regulate blood pressure. Endothelial cells lining resistance arterioles are stimulated to mediate vasodilation when exposed to acetylcholine ( $\mathrm{ACh}$ ) which induces the release of nitric oxide (NO), termed endothelium derived original author(s) and the source, provide a link to the Creative Commons licence, and indicate if changes were made. The images or other third party material in this article are included in the article's Creative Commons licence, unless indicated otherwise in a credit line to the material. If material is not included in the article's Creative Commons licence and your intended use is not permitted by statutory regulation or exceeds the permitted use, you will need to obtain permission directly from the copyright holder. To view a copy of this licence, visit http://creativecommons.org/licenses/by/4.0/. 
relaxing factor or EDRF (Higashi et al. 2012; Mónica et al. 2016). ACh interacts with muscarinic receptors expressed on endothelial cells, and receptor activation induces phosphorylation of endothelial nitric oxide synthase, the rate limiting enzyme in the biosynthesis of NO (Dimmeler et al. 1999; Palmer et al. 1988; Zhou et al. 2005). NO produced by endothelial cells diffuses to adjacent smooth muscle cells, interacts with the heme group in souble guanylate cyclase to stimulate biosynthesis of cGMP, a secondary messenger. CGMP in turn activates signaling cascades to release calcium ion from intracellular stores which produces relaxation of smooth muscle cells and decrease in blood pressure.

While a number of studies have shown that lymphocytes within the circulation (Kawashima and Fujii 2004) as well as the endothelium itself (Kawashima et al. 1990) can produce $\mathrm{ACh}$ and therefore potentially regulate EDRF, serum also contains significant concentrations of ACh (Fujii et al. 1995). Additionally, serum also contains soluble ChAT, the enzyme responsible for ACh biosynthesis, as well as the cholinestarases which degrade $\mathrm{ACh}$ (Vijayaraghavan et al. 2013). Recent study has shown that within the serum (and cerebral spinal fluid) ACh concentration is maintained at a steady state balance via a specific ratio of ChAT to cholinesterases, which varies in different disease states (Vijayaraghavan et al. 2013).

We previously identified a role for an ACh-producing $\mathrm{T}$ cell subset, termed $\mathrm{T}_{\mathrm{ChAT}}$, in regulating blood pressure (Olofsson et al. 2016), as genetic ablation of ChAT in those $\mathrm{T}$ cells produced hypertension (Olofsson et al. 2016). Prior studies have shown that the activation of $T$ cells results in the release of ChAT into the circulation (Vijayaraghavan et al. 2013; Fujii et al. 2017a; Awwad et al. 2014; Speziale et al. 2017). Additionally, it has been observed that decreased ChAT levels and ACh production by lymphocytes occurs in spontaneously hypertensive rats (Fujimoto et al. 2001). Because ACh stimulates EDRF, and increasing serum ACh levels decreases blood pressure in hypertension (Liu et al. 2017; Lataro et al. 2015), we reasoned direct administration of ChAT could tip the balance for increased circulating $\mathrm{ACh}$ and therefore decrease blood pressure in hypertension. We tested this hypothesis in mice by using a continuous infusion of angiotensin II to produce hypertension via its direct effect on the handling of sodium by the kidney (Crowley et al. 2006), while simultaneously administering ChAT and thereby increasing ACh synthesis.

\section{Materials and Methods}

\section{Animals}

All procedures with experimental animals were approved by the Institutional Animal Care and Use Committee and the Institutional Biosafety Committee of the Feinstein
Institutes for Medical Research, Northwell Health, Manhasset, NY in accordance with NIH guidelines. Animals were maintained at $25^{\circ} \mathrm{C}$ on a $12 \mathrm{~h}$ light-dark cycle with free access to food and water. 12-week old male C57BL/6 mice implanted with HD-X10 blood pressure telemeters were obtained from The Jackson Laboratory (Bar Harbor, ME). Mice were singly housed after implanting blood pressure telemeters. ChAT and PEG-ChAT were administered intraperitoneally.

\section{Blood pressure, temperature and activity measurements} Mice were induced under 2.5\% isoflurane and implanted with HD-X10 blood pressure telemeters (Data Sciences Inc., New Brighton, MN) according to the manufacturer's instructions. Briefly, mice were anesthetized and placed in dorsal recumbency. A small incision was made in the neck and the left carotid artery was isolated from the surrounding tissue. A hollow catheter was placed in the left carotid artery and advanced to the aortic arch. Once in place, the catheter was secured to the carotid artery with a suture knot. The telemeter body was placed in a subcutaneous pocket on the animal's flank, and the animal was recovered for 7 days before blood pressure measurements were taken. Surgeries were performed by JAX Surgical Services (The Jackson Laboratory, Bar Harbor, ME).

\section{Angiotensin II administration}

Osmotic pumps (Alzet model 1004, Cupertino CA, 95014) were loaded with angiotensin II (Fisher Scientific) solution to produce the desired flow rate $(700 \mathrm{ng} /$ $\mathrm{kg} / \mathrm{min}$ ) according to the manufacturer's instructions and incubated in sterile saline at $37^{\circ} \mathrm{C}$ for $48 \mathrm{~h}$ before implantation. To implant the pump, mice were induced under $2.5 \%$ isoflurane anesthesia and a $1 \mathrm{~cm}$ midscapular incision was made. The pump was inserted into the midscapular incision and advanced away from the incision site. The incision was closed with a wound clip or sutures. After $24 \mathrm{~h}$ of recovery, blood pressure measurements resumed. After 28 days post-implant, the implants were removed according to the manufacturer's instructions.

\section{Production of recombinant ChAT protein and ChAT PEGylation}

Recombinant human ChAT corresponding to residue 119-748 (EC2.3.1.6, UniProt 28329-3) with a $N$-histidine tag was expressed in E. coli BL21-Gold (DE3) cells. Bacteria were cultured in 2xYT media to an A600 of 0.9. IPTG was added to a final concentration of $3 \mathrm{mM}$ to induce recombinant ChAT production. Five hours later, cells were harvested, re-suspended in cold binding buffer (containing $20 \mathrm{mM}$ Tris, 1\% X-100, pH 8.5) and subjected to sonication at $4{ }^{\circ} \mathrm{C}$. Supernatant was collected by centrifugation at $13,000 \times g$ for $20 \mathrm{~min}$ and applied 
onto a 5-ml high affinity $\mathrm{Ni}$-charged column pre-equilibrated with binding buffer. Following sequential washings with the binding buffer, washing buffer $1(20 \mathrm{mM}$ Tris, $10 \mathrm{mM}$ imidazole, $0.5 \mathrm{M} \mathrm{NaCl}, \mathrm{pH} 8.0$ ), and buffer 2 (0.2× phosphate buffered saline (PBS), $10 \%$ glycerol, $\mathrm{pH}$ 7.5), the recombinant histidine-tagged ChAT protein was eluted with $0.5 \mathrm{M}$ imidazole, $10 \%$ glycerol, in $0.2 \times$ PBS. The recombinant ChAT was further purified by dialysis at $4{ }^{\circ} \mathrm{C}$ in buffer containing $0.2 \times \mathrm{PBS}, 10 \%$ glycerol and 0.5 mM TCEP (tris(2-carboxyethyl)phosphine), and extensive Triton X-114 extraction to remove contaminating endotoxins. PEGylation was performed using an unbranched amine-reactive MS (PEG) 12 reagent (Thermo Scientific), in a buffer containing $10 \%$ glycerol, $0.2 \times$ PBS, $0.5 \mathrm{mM}$ TCEP at a molar ratio of ChAT protein to MS (PEG)12 of 1-200. Following PEGylation, the protein was then dialyzed in buffer and further extracted with Triton X-114 to remove contaminating endotoxins.

\section{Enzyme activity assay}

Activity of recombinant and PEGylated recombinant ChAT was analyzed using an adapted version of the colorimetric assay developed by Kumar et al. (2016). Briefly, ChAT and its substrates choline and acetyl-coenzyme A were incubated at $37^{\circ} \mathrm{C}$ for $15 \mathrm{~min}$ in a total volume of $100 \mu \mathrm{L}$ containing buffer containing $10 \mathrm{mM}$ Tris- $\mathrm{HCl}$, $150 \mathrm{mM} \mathrm{NaCl}, 1 \mathrm{mM}$ EDTA, and $0.05 \%$ Triton X-100 (final concentrations $1.5 \mu \mathrm{g} / \mathrm{mL}$ ChAT, $150 \mu \mathrm{M}$ choline, $150 \mu \mathrm{M}$ acetyl-coenzyme A). After incubation, a cocktail containing choline oxidase, 4-aminoantipyrine, phenol, and horseradish peroxidase (HRP) was added (cocktail concentration $10 \mathrm{U} / \mathrm{mL}$ choline oxidase, $3 \mathrm{mM} 4$-aminoantipyrine, $6 \mathrm{mM}$ phenol, $50 \mathrm{U} / \mathrm{mL}$ HRP). Red color developed in proportion with the remaining choline in the reaction mixture is quantitated spectrophotometrically at $500 \mathrm{~nm}$. By subtracting the remaining choline in wells containing ChAT from the choline remaining in a control well without any enzyme, the reaction rate is calculated.

\section{Data analysis}

Data were analyzed using Graphpad Prism 7.0, Microsoft Excel, DSI Ponemah 6.4, and R. Blood pressure was sampled at $500 \mathrm{~Hz}$ and aggregated into $10 \mathrm{~s}$ bins to calculate SBP, DBP, MAP, and heart rate. Temperature and activity data were separately averaged over $10 \mathrm{~s}$ bins. When averaged over $12 \mathrm{~h}$, data are first binned in $10 \mathrm{~s}$ bins, and $12 \mathrm{~h}$ of bins are averaged together (Figs. 1, 2). When averaged every $20 \mathrm{~min}$, data are first binned and $20 \mathrm{~min}$ of bins are averaged together (Figs. 3D, 4B). When averaged hourly, data are first binned in $10 \mathrm{~s}$ bins, and $60 \mathrm{~min}$ of bins are averaged together (Figs. 3E-G, 4F, Additional file 1: Fig. S7). In all plots, data are presented as mean \pm SEM. Plots were generated using the $\mathrm{R}$ packages ggplot 2 and patchwork. Groups were compared using one-way ANOVA with Dunnett's correction, two-way ANOVA with repeated measures with Sidak's correction, or paired $\mathrm{t}$-test where indicated. $\mathrm{P}$ values $<0.05$ were considered significant.

\section{Results \\ Short- and long-term changes in physiological parameters in hypertensive mice}

A widely used murine preclinical model of essential hypertension is administration of angiotensin II (Ang II) (Simon et al. 1995; Edgley et al. 2001). Here we measured blood pressure in conscious and unrestrained mice using radiotelemetry monitoring of an intraarterial transducer in the aortic arch, which generated high-fidelity blood pressure recordings (Fig. 1A, B). Because mice are nocturnal, mean arterial blood pressure (MAP) during the dark cycle (active cycle for mice) is significantly elevated as compared to the light cycle (MAP: dark cycle $111 \pm 0.6 \mathrm{mmHg}$ vs. light cycle $102 \pm 1.1 \mathrm{mmHg}$, $\mathrm{p}<0.0001$, Fig. 1C, Table 1). Heart rate (HR), core body temperature and activity were also monitored during dark and light cycles using radiotelemetry, revealing significant increases in HR (HR: dark cycle $586 \pm 5$ bpm vs. light cycle $541 \pm 6 \mathrm{bpm}, \mathrm{p}<0.0001$, Fig. 1D), temperature (body temperature: dark cycle $34.7 \pm 0.06{ }^{\circ} \mathrm{C}$ vs. light cycle $34.0 \pm 0.05, \mathrm{p}<0.0001$, Fig. $1 \mathrm{E}$ ), and activity (activity: dark cycle $0.18 \pm 0.01$ abritary units vs. light cycle $0.07 \pm 0.01$ abritary units, $\mathrm{p}<0.0001$, Fig. 1 F).

To induce hypertension, mice were implanted with osmotic pumps delivering Ang II (700 $\mathrm{ng} / \mathrm{kg} / \mathrm{min})$. MAP increases significantly within $24 \mathrm{~h}$ of Ang II pump implantation during both light cycle and dark cycle (Fig. 2A). As observed in normotensive mice (Fig. 1C), MAP during Ang II infusion is significantly higher in the dark cycle (active) than the light cycle (Fig. 2A, Table 1). MAP continues to increase for at least eight days, rising to $136 \pm 1.2 \mathrm{mmHg}$ in the dark cycle $(25 \%$ increase compared to normotensive), and $119 \pm 1.5 \mathrm{mmHg}$ in the light cycle ( $18 \%$ increase compared to normotensive) (Fig. 2A). Significant increases occur in both the systolic blood pressure (SBP) and diastolic blood pressure (DBP) (Fig. 2B, C and Table 1). Compared to normotensive baseline values, both SBP and DBP are increased approximately $25 \%$ in the dark cycle and $18 \%$ in the light cycle (Fig. 2B, C and Table 1). After Ang II infusion, heart rate decreases from $591 \pm 4 \mathrm{bpm}$ to $575 \pm 5 \mathrm{bpm}$ during the dark cycle and from $547 \pm 5 \mathrm{bpm}$ to $526 \pm 4 \mathrm{bpm}$ during the light cycle (Fig. 2D). Body temperature decreases from $34.8 \pm 0.1{ }^{\circ} \mathrm{C}$ to $34.3 \pm 0.1{ }^{\circ} \mathrm{C}$ during the dark cycle, and from $34.5 \pm 0.1{ }^{\circ} \mathrm{C}$ to $33.9 \pm 0.1{ }^{\circ} \mathrm{C}$ during the light cycle (Fig. 2E). Activity is increased in the dark 

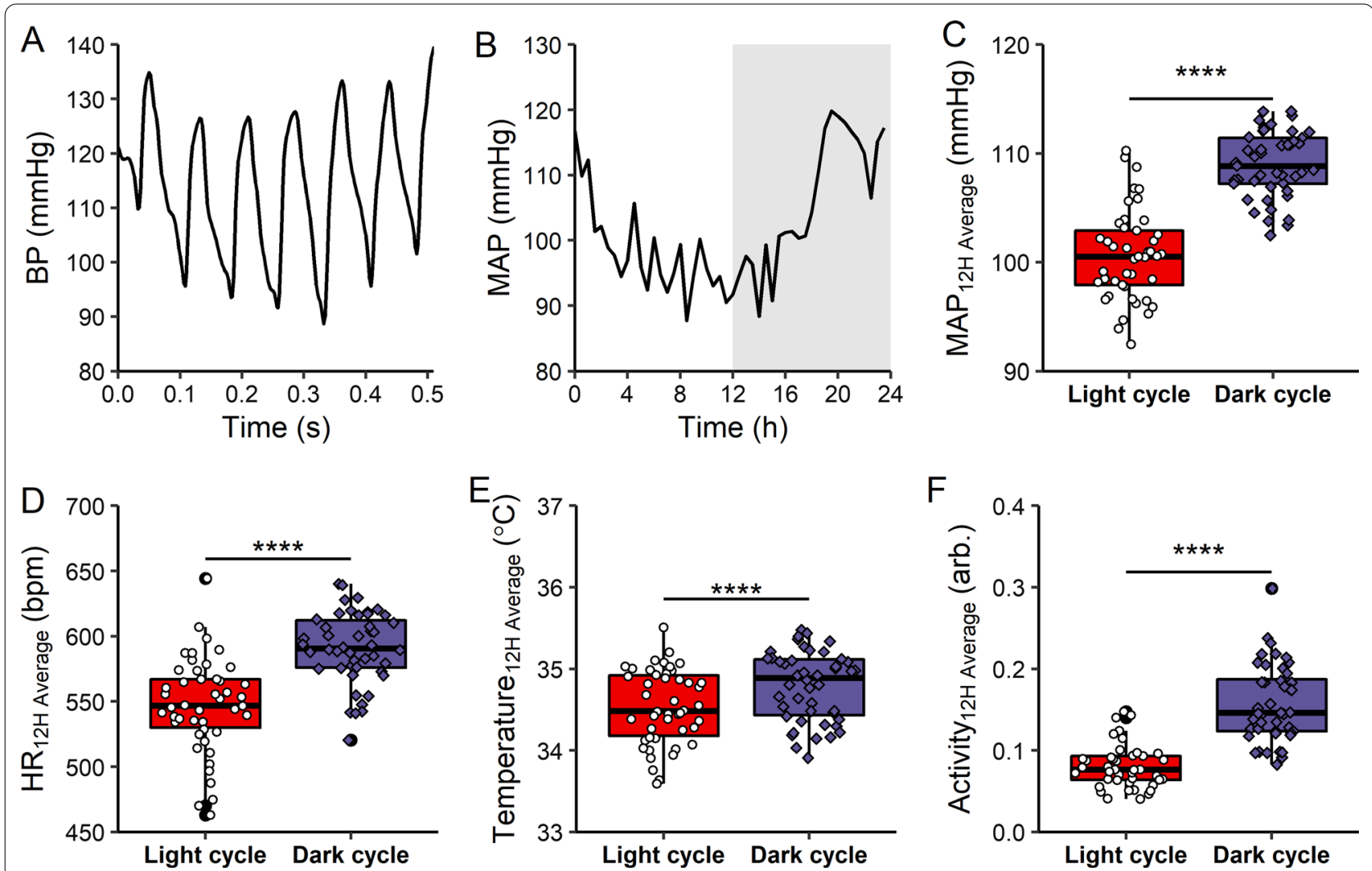

Fig. 1 Telemetry system for analyzing short-term and long-term changes in blood pressure. A representative blood pressure wave tracing from a single telemeter-implanted mouse. BP is measured at $500 \mathrm{~Hz}$. B representative $24 \mathrm{~h}$ tracing of MAP using the same telemeter system. From the blood pressure wave, MAP is calculated every $10 \mathrm{~s}$. These $10 \mathrm{~s}$ bins are averaged over $30 \mathrm{~min}$. Gray background indicates dark cycle when mice are active. $\mathbf{C}$ average normotensive MAP, $\mathbf{D}$ average normotensive HR, $\mathbf{E}$ average normotensive body temperature and $\mathbf{F}$ average normotensive activity. MAP, HR, temperature and activity are analyzed during $12 \mathrm{~h}$ of dark cycle and light cycle. Data are represented as individual mouse data points with mean \pm SEM. $n=44,{ }^{* * * *} p<0.0001$, paired t-test

cycle (from $0.16 \pm 0.01$ units vs $0.19 \pm 0.01$ units), but is decreased during the light cycle (from $0.04 \pm 0.003$ units in normotensive vs $0.06 \pm 0.003$ units in hypertensive, Fig. 2F).

\section{ChAT protein decreases blood pressure in angiotensin II-induced hypertension}

To study the effects of ChAT administration in the context of hypertension, we expressed recombinant human ChAT protein in an Escherichia coli expression system. As expected from the cDNA sequence for the R isoform (UniProt P28329-3), purified ChAT has an observed migration on electrophoresis of approximately $72 \mathrm{kDa}$ (Fig. 3A). To confirm recombinant ChAT protein is functionally active we measured enzyme activity by a colorimetric assay (Kumar et al. 2017) based on depletion of choline from the reaction. Recombinant purified ChAT protein exibits twofold higher specific activity as compared to a commercially available (MyBioSource)
ChAT preparation $(4.26 \pm 0.04 \mathrm{nmol} / \mathrm{min} / \mu \mathrm{g}$ protein $v s$ $1.92 \pm 0.04 \mathrm{nmol} / \mathrm{min} / \mu$ g protein) (Fig. 3B).

Recent clinical data indicates administration of antihypertensive agents at night optimizes blood pressure control and improves cardiovascular risk reduction (Hermida et al. 2019). Accordingly, we administered recombinant ChAT in the middle of the murine sleep cycle, which also corresponded to the time of day with the lowest blood pressure. In the Ang II-induced hypertension model, ChAT administration dose-dependently reduces Ang II-induced elevation of MAP (Fig. 3C), SBP (Additional file 1: Fig. S1A) and DBP (Additional file 1: Fig. $\mathrm{S} 1 \mathrm{~B})$, when measured as area-under-the-curve compared to baseline blood pressures. A single intraperitoneal administration of ChAT $(1 \mathrm{mg} / \mathrm{kg})$ reduces average MAP as compared to vehicle control that lasts for $3 \mathrm{~h}$ postadministration $(121 \pm 4 \mathrm{mmHg}$ vehicle, $107 \pm 8 \mathrm{mmHg}$ ChAT) (Fig. 3D).

As blood pressure is positively correlated with both HR and activity levels (Christofaro et al. 2017; Colangelo 

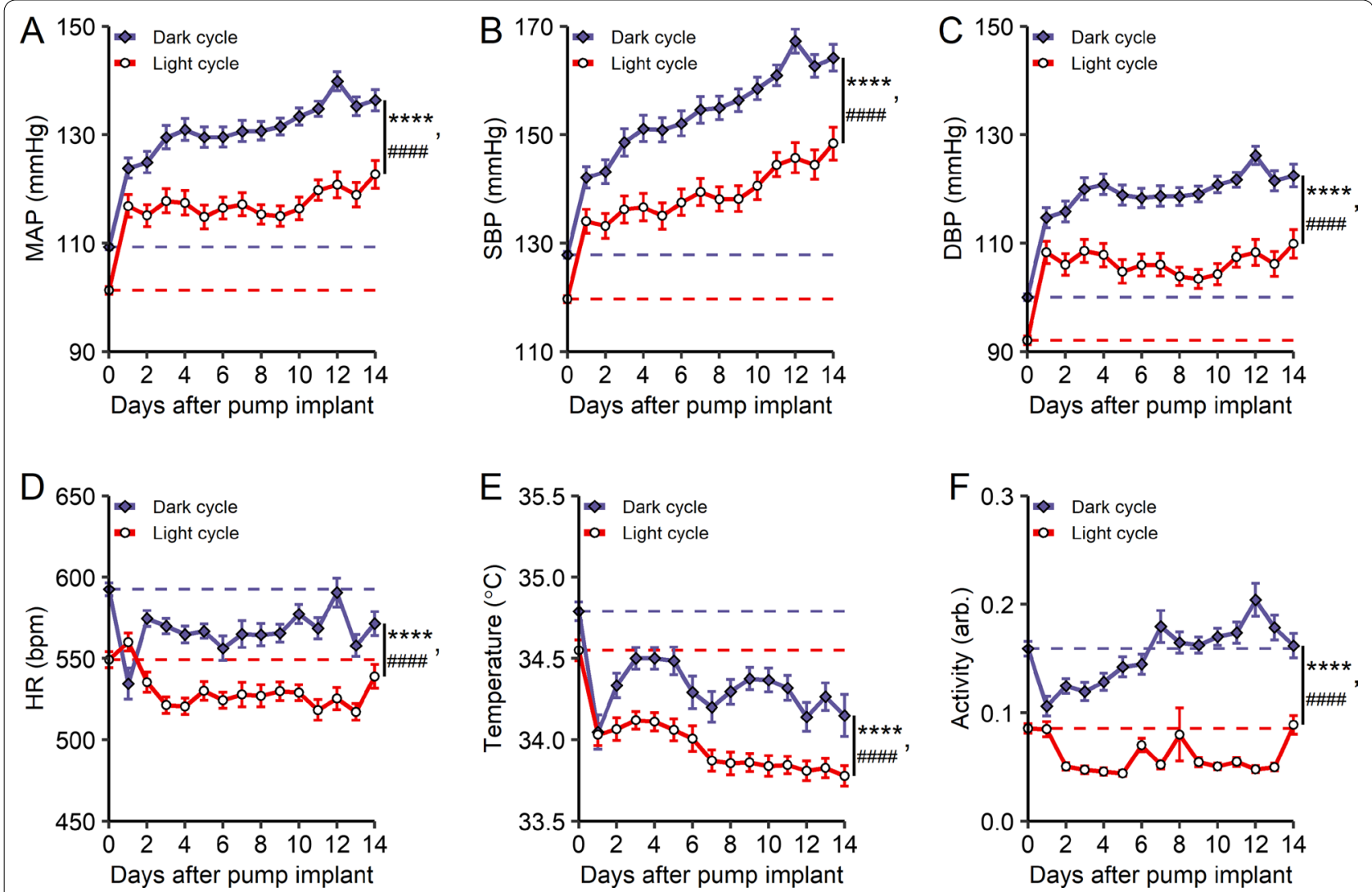

Fig. 2 Angiotensin II-induced hypertension model. A-F change in MAP, SBP, DBP, heart rate, body temperature, and activity levels during angiotensin II infusion. Dark cycle and light cycle average values were collected prior to and during angiotensin II infusion. Osmotic pumps were implanted on day 0 . Data is collected continuously and averaged over the $12 \mathrm{~h}$ light and dark cycles separately on each day. Day 0 values represent an average of 3 days prior to implantation of osmotic pumps delivering angiotensin II. Dashed lines represent data in normotensive animals in light and dark cycles. A MAP, B SBP and C DBP significantly increase during angiotensin II infusion. Data are represented as mean \pm SEM, $n=41-50$, ${ }_{* * *} p<0.0001$, light cycle vs. dark cycle, ${ }^{\# \# \#} \mathrm{p}<0.0001$, over time, two-way ANOVA with Sidak's multiple comparison test. $\mathbf{D}$ HR decreases during angiotensin II infusion. Dark cyle HR remains significantly elevated compared to light cycle HR. Data are represented as mean $\pm S E M, n=41-50$, ${ }_{* * * *} \mathrm{p}<0.0001$, light cycle vs. dark cycle, ${ }^{\# \# \#} \mathrm{p}<0.0001$, over time, two-way ANOVA with Sidak's multiple comparison test. E body temperature decreases during angiotensin II infusion. Dark cycle body temperature remains significantly elevated compared to light cycle body temperature.

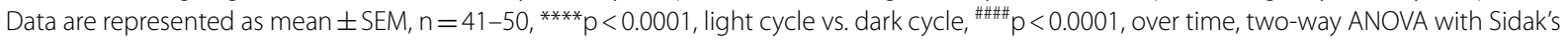
multiple comparison test. $\mathbf{F}$ activity levels decrease during angiotensin II infusion, with dark cycle activity levels remaining significantly elevated compared to light cycle activity levels. Data are represented as mean $\pm S E M, n=41-50,{ }^{* * * *} p<0.0001$, light cycle vs. dark cycle, $\# \# \# \#<0.0001$, over time, two-way ANOVA with Sidak's multiple comparison test

et al. 2020), we assessed changes in HR and activity scores post-ChAT administration. An immediate increase in HR is observed after either vehicle or ChAT administration as a result of intraperitoneal injection stress (Additional file 1: Fig. S2), eventually stabilizing at a level comparable to the vehicle control in the $24 \mathrm{~h}$ post-administration period (Fig. 3E). Unlike HR, body temperature responds slowly to stress and there is no difference in body temperature after ChAT or vehicle administration (Fig. 3F, Additional file 1: Fig. S3). As ChAT was administered in the middle of the light cycle (sleep cycle for mice), the animals are at their minimum activity levels prior to administration. Similar to changes in the HR, an initial increase in the activity levels is observed after injection stress. In the 24-h post-injection period activity levels were significantly increased with ChAT administration compared to vehicle administration (Fig. 3G, Additional file 1: Fig. S4).

The relatively unchanged $\mathrm{HR}$ and activity levels after ChAT administration are consistent with a mechanism of ACh-induced vasorelaxation (Rabelo et al. 2008). ACh acts on muscarinic receptors on endothelial cells, and produces arterial relaxation by activating endothelial nitric oxide synthase that produces NO (Dimmeler et al. 1999). Based on the hypothesis that ChAT administration increases endogenous $\mathrm{ACh}$ production to induce vasorelaxation, we reasoned that ChAT-induced blood 


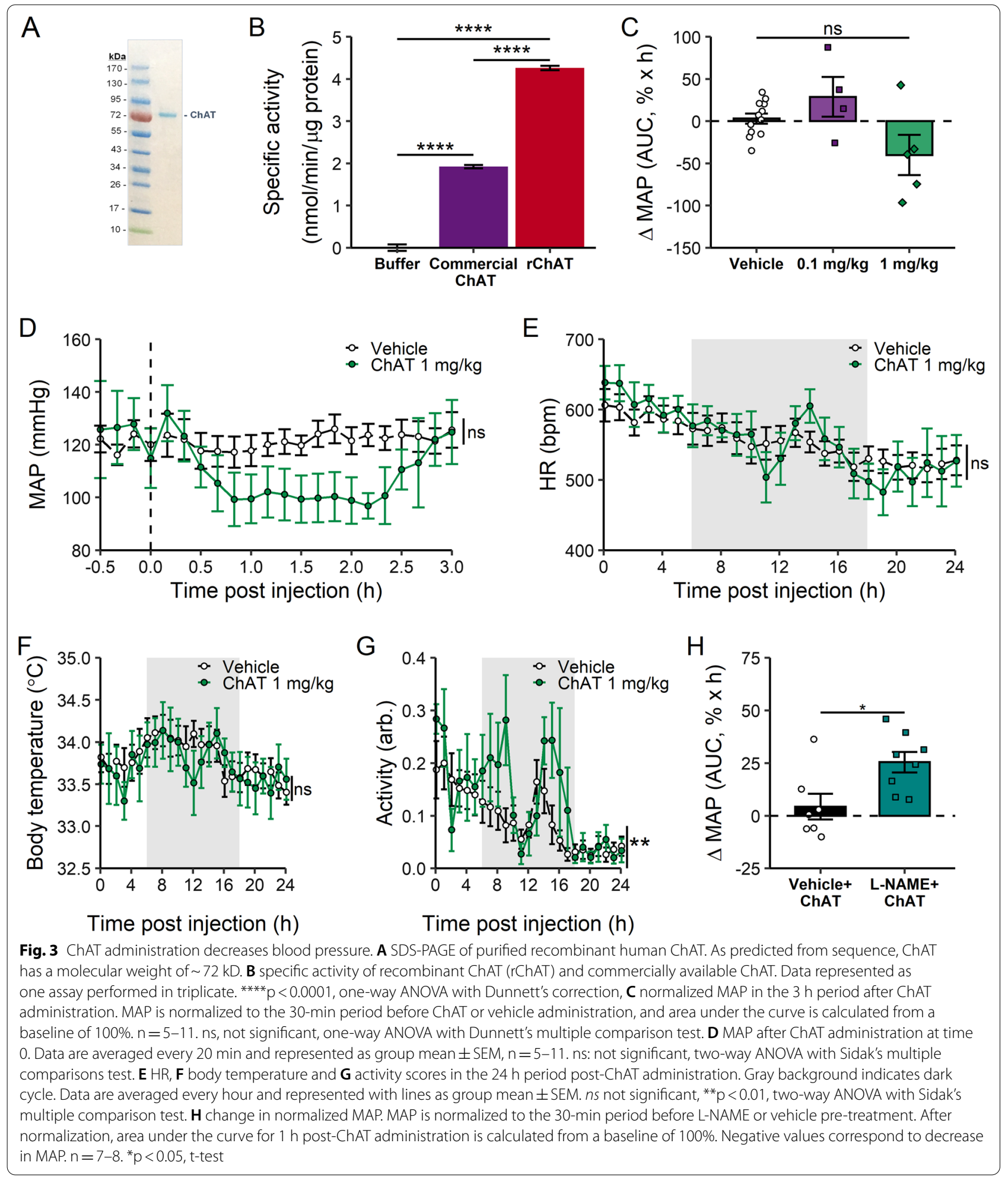

pressure decrease is NO-dependent. To investigate this mechanism, we administered nitric oxide synthase inhibitor No-nitro-L-arginine methyl ester (L-NAME), and measured blood pressure following administration of ChAT. Pre-treatment with L-NAME significantly attenuates ChAT-mediated decrease in blood pressure (Vehicle 


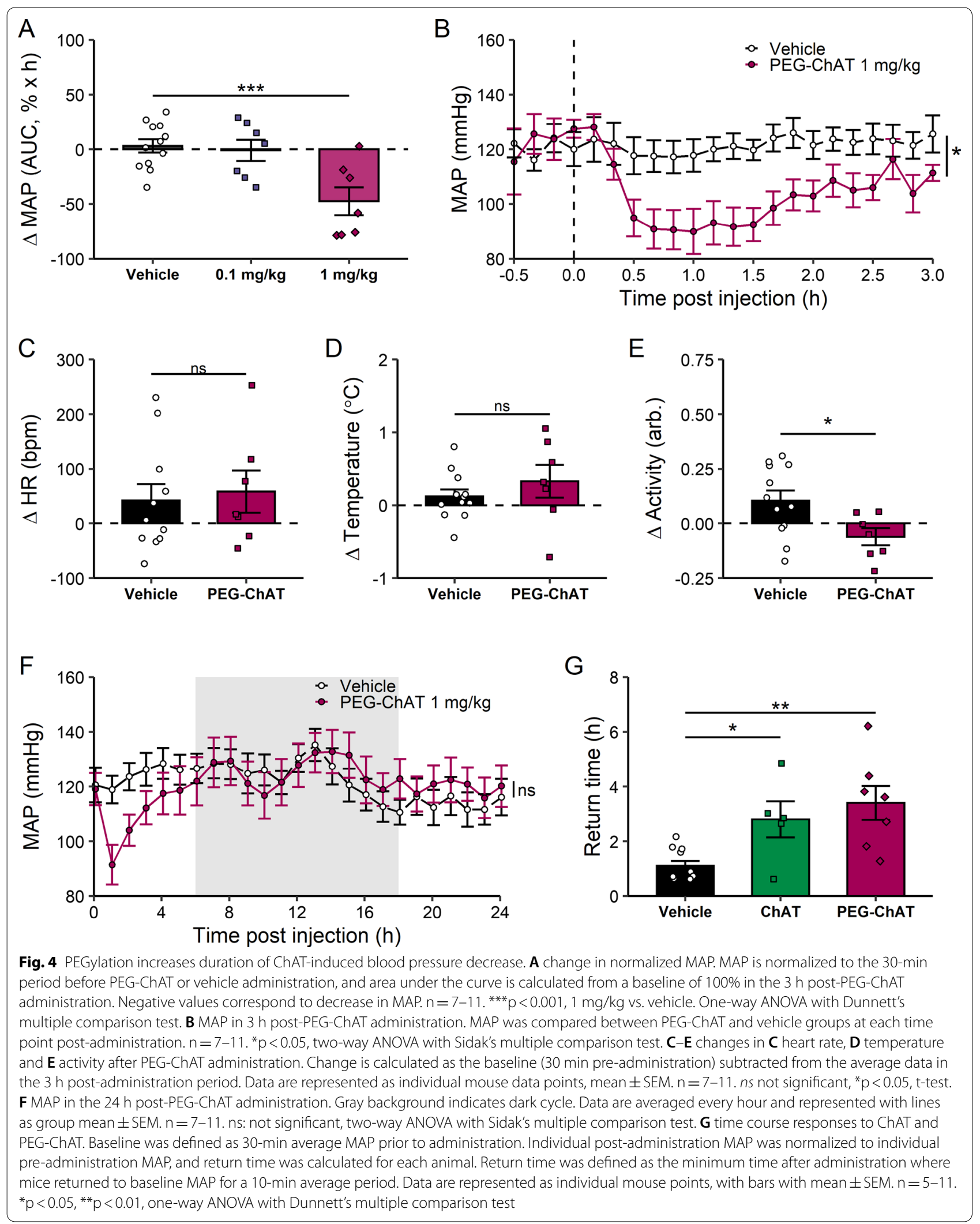


Table 1 Blood pressure in Angiotensin II-induced hypertension model

\begin{tabular}{lllrr}
\hline & & Mean & 95\% Cl & Range \\
\hline MAP, mmHg & & & & \\
Normotensive & Light cycle & 101 & $(99.6-102.5)$ & $92-120$ \\
& Dark cycle & 109 & $(108.3-110.4)$ & $102-123$ \\
Hypertensive & Light cycle & 119 & $(115.8-122.5)$ & $98-150$ \\
& Dark cycle & 136 & $(133.6-139.0)$ & $111-153$ \\
SBP, mmHg & & & & \\
Normotensive & Light cycle & 120 & $(118.3-120.9)$ & $112-134$ \\
& Dark cycle & 128 & $(126.7-129.3)$ & $120-140$ \\
Hypertensive & Light cycle & 144 & $(139.7-147.8)$ & $119-172$ \\
& Dark cycle & 163 & $(159.2-166.4)$ & $131-185$ \\
DBP, mmHg & & & & \\
Normotensive & Light cycle & 92 & $(90.0-93.5)$ & $82-112$ \\
& Dark cycle & 100 & $(98.8-101.2)$ & $92-114$ \\
Hypertensive & Light cycle & 107 & $(103.5-110.1)$ & $87-139$ \\
& Dark cycle & 123 & $(120.4-125.7)$ & $102-141$ \\
\hline
\end{tabular}

vs L-NAME: $4.3 \pm 6.1 \%$ MAP $\times$ h vs $25.4 \pm 4.9 \%$ MAP $\times$ $\mathrm{h}, \mathrm{p}=0.019$, Fig. $3 \mathrm{H})$. Together, these results indicate administration of recombinant ChAT decreases blood pressure through a NO-mediated endothelium-dependent vasorelaxation mechanism.

\section{PEGylated ChAT retains activity and decreases blood pressure}

To prolong the half life, ChAT was modified by covalently attaching repeating units of polyethylene glycol (PEG). This method is a useful strategy to enhance the pharmacokinetic properties of therapeutic proteins as it increases protein's hydrodynamic radius and decreases immunogenicity and proteolysis (Jevševar et al. 2010; Veronese 2001; Simone 2008). Recombinant ChAT was pegylated using an amine-reactive PEG reagent to generate PEGylated ChAT (PEG-ChAT) with a molecular weight of approximately $95 \mathrm{kDa}, \mathrm{a} \sim 20 \mathrm{kD}$ increase compared to recombinant ChAT (Additional file 1: Fig. S5A). The enzymatic activity of PEG-ChAT was confirmed using the colorimetric assay, indicating pegylated protein retains the activity to catalyze ACh production (Specific activity: $4.45 \pm 0.03 \mathrm{nmol} /$ $\mathrm{min} / \mu \mathrm{g}$ ChAT vs $4.25 \pm 0.04 \mathrm{nmol} / \mathrm{min} / \mu \mathrm{g}$ PEGChAT) (Additional file 1: Fig. S5B). When given to mice, a single dose of PEG-ChAT in the middle of the light cycle (sleep cycle) reduces Ang II-induced elevation of MAP (vehicle vs $1 \mathrm{mg} / \mathrm{kg}$ PEG-ChAT: $3.16 \pm 6.03 \%$ MAP AUC $\times$ h vs $-47.5 \pm 12.6 \%$ MAP $\times$ h, p < 0.001, Fig. 4A), SBP and DBP (Additional file 1: Fig. S6A, B). A single intraperitoneal administration of PEG-ChAT $(1 \mathrm{mg} / \mathrm{kg})$ significantly reduces MAP as compared to vehicle administration that lasts for $3 \mathrm{~h}$ post-administration (MAP: $121 \pm 4.5 \mathrm{mmHg}$ vehicle vs $102 \pm 4 \mathrm{mmHg}$ PEG-ChAT $1 \mathrm{mg} / \mathrm{kg}, \mathrm{p}<0.05$, Fig. 4B). PEG-ChAT fails to significantly increase HR (Fig. 4C) $(30 \pm 30 \mathrm{bpm}$ for vehicle, $59 \pm 39 \mathrm{bpm}$ PEG-ChAT, Fig. $4 \mathrm{C})$, and alter body temperature $\left(0.12 \pm 0.09^{\circ} \mathrm{C}\right.$ for vehicle, $0.33 \pm 0.22{ }^{\circ} \mathrm{C}$ PEG-ChAT, Fig. $4 \mathrm{D}$ ) in the 3-h period post-administration. Interestingly, PEG-ChAT decreases activity as compared to pre-administration levels $(0.1 \pm 0.05$ units vehicle vs $-0.06 \pm 0.04$ units PEG-ChAT, $\mathrm{p}<0.05$, Fig. $4 \mathrm{E}$ ), but this change in activity levels is transient and not seen in the $24 \mathrm{~h}$ period post-administration (Additional file 1: Fig. S7C). A single dose of PEG-ChAT decreases in MAP persist for $3 \mathrm{~h}$ (Fig. 4F), and also does not induce lasting changes in $\mathrm{HR}$, body temperature or activity scores (Additional file 1: Fig S7A-C). Finally, to assess the duration of responses to ChAT and PEG-ChAT, we normalized individual post-administration MAP to individual preadministration MAP, and calculated return time to pre-administration MAP for each animal. A significant increase in return time is observed after either ChAT or PEG-ChAT administration as compared to vehicle controls (Fig. 4G). An increased return time is observed after PEG-ChAT administration, indicating that PEGChAT maintains the lower MAP for a longer time $(2.8 \pm 0.7$ h ChAT, $3.4 \pm 0.6$ h PEG-ChAT, Fig. 4 G).

\section{Effect of ChAT depends on the time of administration}

Next, we assessed whether administration of ChAT or PEG-ChAT during the dark cycle when the blood pressure is at its peak levels, reduces MAP in Ang IIinduced hypertensive mice. We administered recombinant ChAT or PEG-ChAT in the middle of the dark cycle (active cycle for mice), which corresponded to the time of the day with highest blood pressures (Fig. 1B). In the Ang II-induced hypertension model, a single administration of ChAT does not induce significant decreases in MAP when given during the dark cycle (Fig. 5A). However, when assessed over the entire 24-h period following ChAT administration, ChAT induces a persistant decrease in MAP (Fig. 5B). In contrast, administration of PEG-ChAT during the dark cycle induces a significant dose-dependent decrease in MAP that persists for at least $24 \mathrm{~h}$ (Fig. 5C, D). Interestingly, lower doses of PEG-ChAT induce larger changes in MAP (Fig. 5C, D). In the $12 \mathrm{~h}$ light cycle following active-cycle administration, MAP was decreased to near normotensive levels with a single administration of PEG-ChAT (Figs. 1C, 5D). Accordingly, a persistent decrease in SBP and DBP is observed after 

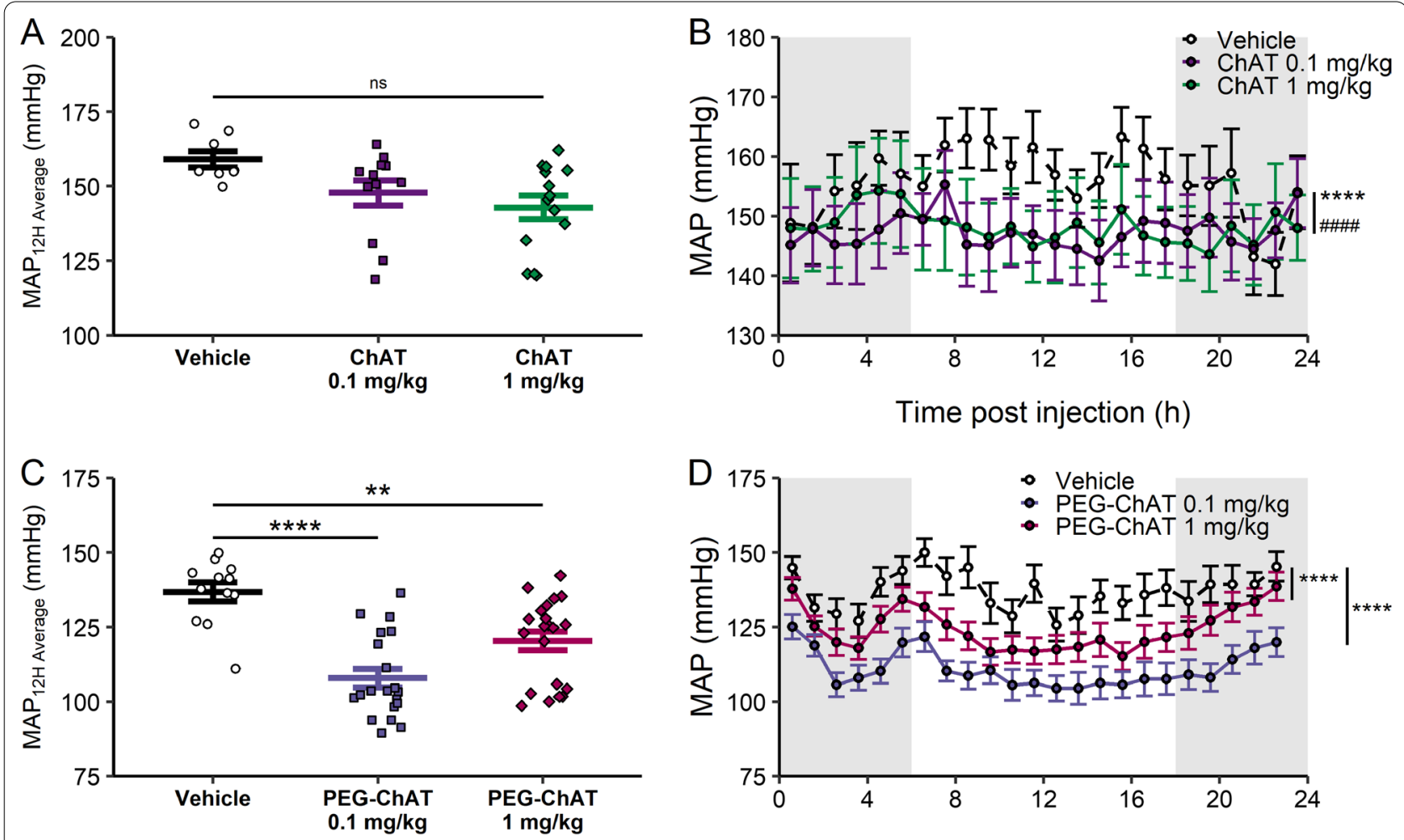

Time post injection (h)

Fig. 5 Administration of PEG-ChAT during dark cycle (active cycle) decreases blood pressure. A mean MAP in light cycle following a dark cycle administration of ChAT. ChAT was administered in the middle of the dark cycle (6 h), and MAP is averaged 6-18 h post-ChAT administration. Data are represented as individual mouse points with mean \pm SEM. $n=8-15$. ns not significant, one-way ANOVA with Dunnett's multiple comparison test. B MAP in $24 \mathrm{~h}$ post-ChAT administration in dark cycle. Gray background indicates dark cycle. Data are averaged every hour and represented with lines as group mean \pm SEM. $n=8-15 .{ }^{* * *} \mathrm{p}<0.0001$, vehicle vs. $0.1 \mathrm{mg} / \mathrm{kg}$ ChAT, \#\#\#\# $\mathrm{p}<0.0001$, vehicle vs. $1 \mathrm{mg} / \mathrm{kg}$ ChAT, two-way ANOVA with Tukey's multiple comparison test. $\mathbf{C}$ mean MAP in light cycle following a dark cycle administration of PEG-ChAT. PEG-ChAT was administered in the middle of the dark cycle $(6 \mathrm{~h})$, and MAP is averaged $6-18 \mathrm{~h}$ post-ChAT administration. Data are represented as individual mouse points with mean \pm SEM. $n=12-21 .{ }^{* *} p<0.01,{ }^{* * * *} p<0.0001$, one-way ANOVA with Dunnett's multiple comparison test. D MAP in $24 \mathrm{~h}$ post-PEG-ChAT administration in dark cycle. Gray background indicates dark cycle. While there is no initial transient BP decrease, MAP is decreased during the next light cycle phase. Data are averaged every hour and represented with lines as group mean \pm SEM. $n=12-21 .{ }^{* * *} p<0.0001$, vehicle vs. $0.1 \mathrm{mg} / \mathrm{kg}$ or $1 \mathrm{mg} / \mathrm{kg}$ PEG-ChAT, two-way ANOVA with Tukey's multiple comparison test

administration of PEG-ChAT in the dark cycle (Additional file 1: Fig. S8A, 8B).

\section{Discussion}

Here we report that administration of PEG-ChAT to mice with Ang II-induced hypertension significantly attenuates increases in MAP, SBP and DBP without altering other physiological parameters including $\mathrm{HR}$, temperature and activity. These findings reveal the previously unrecognized potential use of exogenous ChAT as an experimental therapeutic in hypertension. Chronic infusion of Ang II in experimental animals induces a gradual increase in blood pressure (Simon et al. 1995; Romero and Reckelhoff 1999) primarily via its effect on angiotensin receptor 1 in the kidney (Crowley et al. 2006) and is widely used as a preclinical model for studies of cardiovascular physiology (Lerman et al. 1979; Lohmeier 2012). As expected, we observed that infusion of Ang II over a 2-week period in mice causes the gradual development of hypertension with associated changes in HR, body temperature and activity scores.

Despite extensive studies on ACh-mediated vasorelaxation, its role as a therapeutic strategy for cardiovascular diseases, especially in hypertension is not well-characterized. Conventional hypertension therapies focus on strategies for attenuating the activity of the renin-angiotensin system or by decreasing sympathetic nerve activity, because adrenergic neurons mediate vasoconstriction and increased peripheral resistance. However, increased parasympathetic vagus nerve cholinergic activity has been correlated with an improvement 
in endothelial dysfunction and aortic stiffening in spontaneously hypertensive rats (Annoni et al. 2019). Choline administration also slows the progression of hypertension in preclinical models, possibly by enhancing vagus nerve activity (Liu et al. 2017). Because the serum half-life of ACh is short (on the order of minutes), and because the vasculature is innervated by adrenergic and not cholinergic nerve fibers, the discovery of ACh-producing $\mathrm{T}$ cells provided an important new insight into cholinergic mechanisms of NO-dependent vasorelaxation (Sheng and Zhu 2018). ChAT-expressing CD4 T cells $\left(\mathrm{CD} 4 \mathrm{~T}_{\mathrm{ChAT}}\right)$ are required to maintain normotension in mice via a NO-dependent mechanism. Ablation of ChAT in CD4 $\mathrm{T}$ cells leads to chronic hypertension indicating that ChAT expression by $\mathrm{T}$ cells is required to deliver $\mathrm{ACh}$ to endothelium devoid of direct cholinergic innervation (Olofsson et al. 2016).

ChAT is present as both an intracellular cytosolic enzyme in cholinergic cells and within extracellular compartments, incuding human plasma (Vijayaraghavan et al. 2013). Previous study has shown that in humans, soluble ChAT within the plasma and cerebrospinal fluid maintains a steady-state equilibrium of extrasynaptic $\mathrm{ACh}$ in the presence of ACh degrading enzymes, acetylcholinesterase and butyrylcholinesterase (Vijayaraghavan et al. 2013). Our finding that ChAT attenuates elevated blood pressure provides a possible explanation for ACh-mediated vasorelaxation through continuous renewal of $\mathrm{ACh}$ in the vasculature by soluble $\mathrm{ChAT}$, and thereby maintenance of cardiovascular homeostasis in the absence of direct innervation with the cholinergic nerve fibers. These findings also suggest that deficiencies in, or impairment of, circulating ChAT may contribute to the pathogenesis of hypertension. Reduced ChAT expression in circulating lymphocytes and lymphoid organs has been previously linked to hypertension (Fujimoto et al. 2001).

In addition to the endothelium, plasma ACh has access to other cells which express ACh receptors. For example, erythrocytes express muscarinic receptors which, when activated by $\mathrm{ACh}$, increase nitric oxide levels (Carvalho et al. 2004). Additionally, platelets, and both $\mathrm{T}$ and $\mathrm{B}$ lymphocytes respond to ACh raising the possibility of autocrine and paracrine regulation of immune function (Schedel et al. 2011; Fujii et al. 2017b). These and other biological activities distinct from those of the endothelium which are potentially modulated by circulating concentrations of $\mathrm{ACh}$ will require additional study to determine whether significant adverse effects occur following a change in plasma ChAT concentration.

In these acute experiments biological half-life following enzyme administration is relatively short lived, lasting several hours. The half life will need to be more quantitatively assessed following repeated dosing and the profile of blood pressure response followed to determine whether administration of unmodified ChAT could be a viable pharmaceutical intervention. More than likely, modifications to prolong half life or development of a delayed release formulation will be required. Notably, in these acute experiments pegylation of the enzyme, one of a variety of commonly used biochemical modifications to increase circulating half life of short lived compounds, results in retained enzymatic activity which provided moderately longer-lasting decrease in blood pressure than the unmodified enzyme. Finally, evalaution of ChAT administraton with currently utilized anti-hypertensives which target the underlying pathophysiology, particularly angiotensin converting enzyme inhibitors or angiotensin receptor blockers would be important to undertake.

In conclusion, our studies show that systemic administration of recombinant ChAT to mice with angiotensin IIinduced hypertension significantly, dose-dependently and acutely decreases mean arterial pressure. ChAT-induced attenuation of blood pressure is reversed by inhibiting nitic oxide production, indicating that ChAT administration reduces blood pressure through nitic oxidedependent vasodilation. Administration of PEG-ChAT to hypertensive mice decreased mean arterial pressure with a significantly longer response duration as compared to ChAT. The possible role of pegylation to improve the efficacy of ChAT as shown in the current study, should be thoroughly examined as a strategy to modify the halflife and efficacy of ChAT. These findings are of interest for the development of ChAT as a novel therapeutic for established hypertension.

\section{Abbreviations}

BP: Blood pressure; SBP: Systolic blood pressure; DBP: Diastolic blood pressure; MAP: Mean arterial blood pressure; ChAT: Choline acetyltransferase; NO: Nitric oxide; PEG: Polyethylene glycol; EDRF: Endothelium derived relaxation factor; $\mathrm{T}_{\text {ChAT }}$ : T-choline acetyltransferase; Angll: Angiotensin II; HR: Heart rate; L-NAME: $\mathrm{N} \omega$-nitro-L-arginine methyl ester.

\section{Supplementary Information}

The online version contains supplementary material available at https://doi. org/10.1186/s10020-021-00380-6.

\footnotetext{
Additional file 1: Figure S1. ChAT administration decreases SBP and DBP. A Change in normalized SBP in the $3 \mathrm{~h}$ period after ChAT administration. SBP is normalized to the 30-min period before ChAT or vehicle administration. After normalization, area under the curve is calculated from a baseline of 100\%. Negative values correspond to decrease in SBP. $n=7-11 .{ }^{*} p<0.05$, one-way ANOVA with Dunnett's correction. B Change in normalized DBP in the $3 \mathrm{~h}$ period after ChAT administration. DBP is normalized to the 30-min period before ChAT or vehicle administration. After normalization, area under the curve is calculated from a baseline of $100 \%$. Negative values correspond to decrease in DBP. Data are represented as individual mouse data points, mean \pm SEM. $n=7-11$. ns not significant one-way ANOVA with Dunnett's correction. Figure S2. ChAT administration increases heart rate. Change in heart rate after ChAT administration.
} 
Heart rate is averaged over the 30 min pre-administration. Change is calculated as the pre-administration baseline subtracted from the average heart rate in the $3 \mathrm{~h}$ post-administration period. Data are represented as individual mouse data points, mean \pm SEM. $n=5-11,{ }^{*} p<0.05$, t-test. Figure S3. ChAT administration does not affect body temperature. Change in body temperature after ChAT administration. Body temperature is averaged over the $30 \mathrm{~min}$ pre-administration. Change is calculated as the preadministration baseline subtracted from the average body temperature in the $3 \mathrm{~h}$ post-administration period. Data are represented as individual mouse data points, mean \pm SEM. $n=5-11$, ns not significant, t-test. Figure S4. ChAT administration increases activity levels. Change in activity after ChAT administration. Activity is averaged over the $30 \mathrm{~min}$ preadministration. Change is calculated as the pre-administration baseline subtracted from the average activity in the $3 \mathrm{~h}$ post-administration period. Data are represented as individual mouse data points, mean \pm SEM. Vehicle $n=5-11$, $n$ s not significant, t-test. Figure S5. PEGylation increases molecular weight without decreasing specific activity. A SDS-PAGE of purified recombinant human ChAT with and without PEGylation. With PEGylation, molecular weight increases by approximately $20 \mathrm{kDa}$. B comparison of specific activity of ChAT and PEG-ChAT, as determined by colorimetric activity assay. Data represented as one assay performed in triplicate. ${ }^{* * *} \mathrm{p}<0.0001$, one-way ANOVA with Dunnett's correction. Figure S6. PEG-ChAT administration decreases both SBP and DBP. A change in normalized SBP in the $3 \mathrm{~h}$ period after PEG-ChAT administration. SBP is normalized to the 30 -min period before PEG-ChAT (0.1 or $1 \mathrm{mg} / \mathrm{kg}$ ) or vehicle administration, and area under the curve is calculated from a baseline of 100\%. Negative values correspond to decrease in SBP. Data are represented as individual mouse data points, mean \pm SEM. $n=7-11$ per group. ${ }^{* *} p<0.001$, one-way ANOVA with Dunnett's correction. B change in normalized DBP in the $3 \mathrm{~h}$ period after PEG-ChAT administration. SBP is normalized to the 30-min period before PEG-ChAT ( $0.1 \mathrm{or} 1 \mathrm{mg} / \mathrm{kg}$ ) or vehicle administration, and area under the curve is calculated from a baseline of 100\%. Negative values correspond to decrease in DBP. Data are represented as individual mouse data points, mean \pm SEM. $n=7-11$ per group. ${ }^{* *} p<0.01$, one-way ANOVA with Dunnett's correction. Figure S7. PEG-ChAT administration does not induce long-term changes in heart rate, body temperature, or activity levels. A HR, $\mathbf{B}$ temperature and $\mathbf{C}$ activity in the $24 \mathrm{~h}$ period post PEG-ChAT administration. Gray background indicates dark cycle. Data are averaged every hour and represented with lines as group mean \pm SEM. ns not significant, two-way ANOVA with Sidak's multiple comparisons test. Figure S8. PEG-ChAT administration during dark cycle induces decreases in SBP and DBP in the following light cycle. A mean SBP, B mean DBP in light cycle. PEG-ChAT was administered at the middle of the dark cycle ( $6 \mathrm{~h})$, and MAP is averaged $6-18 \mathrm{~h}$ post-PEG-ChAT administration. Data are represented as individual mouse data points, mean \pm SEM. Vehicle: $n=12$, PEG-ChAT $0.1 \mathrm{mg} / \mathrm{kg}: \mathrm{n}=20$, PEG-ChAT $1 \mathrm{mg} / \mathrm{kg}: \mathrm{n}=21,{ }^{*} \mathrm{p}<0.05,{ }^{* * *} \mathrm{p}<0.001,{ }^{* * * *} \mathrm{p}<0.0001$, one-way ANOVA with Dunnett's correction.

\section{Acknowledgements}

We thank Eric Chang and Valentin Pavlov from The Feinstein Institutes for Medical Research for helpful discussions.

\section{Authors' contributions}

KJT and SSC conceived project. AS, KJT and SSC designed experiments, interpreted data, and wrote the paper. AS, VS, TT, AT and HY performed experiments and analyzed data. JL prepared recombinant ChAT and PEG-ChAT. MB and YT provided comments, participated in additional discussions, and helped to write and finalize the manuscript. All authors read and approved the final manuscript.

\section{Availability of data and materials}

The datasets used and/or analysed during the current study are available from the corresponding author on reasonable request.

\section{Declarations}

\section{Ethics approval and consent to participate}

All procedures with experimental animals were approved by the Institutional Animal Care and Use Committee and the Institutional Biosafety Committee of the Feinstein Institutes for Medical Research, Northwell Health, Manhasset, NY in accordance with $\mathrm{NIH}$ guidelines.

\section{Consent for publication}

Not applicable.

\section{Competing interests}

AS, JL, KJT and SSC have filed a patent application relevant to this work and have assigned their rights to the Feinstein Institutes for Medical Research. YT is an employee of Circulatory Therapeutics.

\section{Author details}

${ }^{1}$ Institute of Bioelectronic Medicine, The Feinstein Institutes for Medical Research, Northwell Health, 350 Community Drive, Manhasset, NY 11030, USA. ${ }^{2}$ Donald and Barbara Zucker School of Medicine at Hofstra/Northwell, 350 Community Drive, Manhasset, NY 11030, USA. ${ }^{3}$ Circulatory Technology, Inc, 21 Singworth St, Oyster Bay, NY 11771, USA. ${ }^{4}$ The Elmezzi Graduate School of Molecular Medicine, Northwell Health, 350 Community Drive, Manhasset, NY 11030, USA.

\section{Received: 30 April 2021 Accepted: 11 September 2021}

Published online: 21 October 2021

\section{References}

Annoni EM, Van Helden D, Guo Y, Levac B, Libbus I, KenKnight BH, et al. Chronic low-level vagus nerve stimulation improves long-term survival in saltsensitive hypertensive rats. Front Physiol. 2019;10(JAN):25.

Awwad HM, Kirsch SH, Geisel J, Obeid R. Measurement of concentrations of whole blood levels of choline, betaine, and dimethylglycine and their relations to plasma levels. J Chromatogr . 2014;957:41-5.

Carvalho F, Mesquita R, Martins-Silva J, Saldanha C. Acetylcholine and choline effects on erythrocyte nitrite and nitrate levels. J Appl Toxicol. 2004;24(6):419-27.

Christofaro DGD, Casonatto J, Vanderlei LCM, Cucato GG, Dias RMR. Relationship between resting heart rate, blood pressure and pulse pressure in adolescents. Arq Bras Cardiol. 2017;108(5):405-10.

Colangelo LA, Yano Y, Jacobs DR, Lloyd-Jones DM. Association of resting heart rate with blood pressure and incident hypertension over 30 years in black and white adults: the CARDIA Study. Hypertension. 2020;76(3):692-8.

Crowley S, Gurley S, Herrera M, Ruiz P, Griffiths R, Kumar A, et al. Angiotensin Il causes hypertension and cardiac hypertrophy through its receptors in the kidney. Proc Natl Acad Sci USA. 2006;103(47):17985-90.

Dimmeler S, Fleming I, Fisslthaler B, Hermann C, Busse R, Zeiher AM. Activation of nitric oxide synthase in endothelial cells by Akt-dependent phosphorylation. Nature. 1999;399(6736):601-5.

Edgley A, Kett M, Anderson W. "Slow pressor" hypertension from lowdose chronic angiotensin II infusion. Clin Exp Pharmacol Physiol. 2001;28(12):1035-9.

Fujii T, Yamada S, Yamaguchi N, Fujimoto K, Suzuki T, Kawashima K. Species differences in the concentration of acetylcholine, a neurotransmitter, in whole blood and plasma. Neurosci Lett. 1995;201(3):207-10.

Fujii T, Mashimo M, Moriwaki Y, Misawa H, Ono S, Horiguchi K, et al. Expression and function of the cholinergic system in immune cells. Front Immunol. 2017a;8(SEP):1-18.

Fujii T, Mashimo M, Moriwaki Y, Misawa H, Ono S, Horiguchi K, et al. Physiological functions of the cholinergic system in immune cells. J Pharmacol Sci. 2017b;134(1):1-21.

Fujimoto K, Matsui M, Fujii T, Kawashima K. Decreased acetylcholine content and choline acetyltransferase mRNA expression in circulating mononuclear leukocytes and lymphoid organs of the spontaneously hypertensive rat. Life Sci. 2001;69(14):1629-38. 
González A, Ravassa S, López B, Moreno MU, Beaumont J, San José $\mathrm{G}$, et al. Myocardial remodeling in hypertension. Hypertension. 2018;72(3):549-58.

Hermida RC, Crespo JJ, Domínguez-Sardiña M, Otero A, Moyá A, Ríos MT, et al. Bedtime hypertension treatment improves cardiovascular risk reduction: the Hygia Chronotherapy Trial. Eur Heart J. 2019. https://doi.org/10.1093/ eurheartj/ehz754.

Higashi Y, Kihara Y, Noma K. Endothelial dysfunction and hypertension in aging. Hypertens Res. 2012;35:1039-47.

Jevševar S, Kunstelj M, Porekar VG. PEGylation of therapeutic proteins. Biotechnol J. 2010;5(1):113-28.

Kawashima K, Fujii T. Expression of non-neuronal acetylcholine in lymphocytes and its contribution to the regulation of immune function. Front Biosci. 2004;9:2063-85.

Kawashima K, Watanabe N, Oohata H, Fujimoto K, Suzuki T, Ishizaki Y, et al. Synthesis and release of acetylcholine by cultured bovine arterial endothelial cells. Neurosci Lett. 1990;119(2):156-8.

Kumar R, Långström B, Darreh-Shori T. Novel ligands of Choline Acetyltransferase designed by in silico molecular docking, hologram QSAR and lead optimization. Sci Rep. 2016;6(1):31247.

Kumar R, Kumar A, Långström B, Darreh-Shori T. Discovery of novel choline acetyltransferase inhibitors using structure-based virtual screening. Sci Rep. 2017;7(1):1-17

Lataro RM, Silva CAA, Tefé-Silva C, Prado CM, Salgado HC. Acetylcholinesterase inhibition attenuates the development of hypertension and inflammation in spontaneously hypertensive rats. Am J Hypertens. 2015;28(10):1201-8.

Lerman LO, Kurtz TW, Touyz RM, Ellison DH, Chade AR, Crowley SD, et al. Animal models of hypertension. Hypertension (Dallas, Tex 1979). 2019;73(6):e87-120.

Liu L, Lu Y, Bi X, Xu M, Yu X, Xue R, et al. Choline ameliorates cardiovascular damage by improving vagal activity and inhibiting the inflammatory response in spontaneously hypertensive rats. Sci Rep. 2017;7(1):42553.

Lohmeier TE. Angiotensin II infusion model of hypertension: is there an important sympathetic component? Hypertension. 2012;59(3):539-41.

Mónica FZ, Bian K, Murad F. The endothelium-dependent nitric oxide-cGMP pathway. In: Advances in pharmacology. Cambridge: Academic Press Inc.; 2016. p. 1-27.

Mozaffarian D, Benjamin EJ, Go AS, Arnett DK, Blaha MJ, Cushman M, et al. Heart disease and stroke statistics-2015 update: a report from the American Heart Association. Circulation. 2015;131(4):e29-39.

Olofsson PS, Steinberg BE, Sobbi R, Cox MA, Ahmed MN, Oswald M, et al. Blood pressure regulation by CD4+ lymphocytes expressing choline acetyltransferase. Nat Biotechnol. 2016;34(10):1066-71.

Palmer RMJ, Ashton DS, Moncada S. Vascular endothelial cells synthesize nitric oxide from L-arginine. Nature. 1988;333:664-6.

Pugh D, Gallacher PJ, Dhaun N. Management of Hypertension in chronic kidney disease. Drugs. 2019;79(4):365-79.
Rabelo ER, Rohde LE, Schaan BD, Rubira MC, Ruschel KB, Plentz RDM, et al. Bradykinin or acetylcholine as vasodilators to test endothelial venous function in healthy subjects. Clinics. 2008;63(5):677-82.

Romero JC, Reckelhoff JF. Role of angiotensin and oxidative stress in essential hypertension. Hypertension. 1999;34:943-9.

Schedel A, Thornton S, Schloss P, Klüter H, Bugert P. Human platelets express functional a7-nicotinic acetylcholine receptors. Arterioscler Thromb Vasc Biol. 2011;31(4):928-34.

Sheng Y, Zhu L. The crosstalk between autonomic nervous system and blood vessels. Int J Physiol Pathophysiol Pharmacol. 2018;10(1):17-28.

Simon G, Abraham G, Cserep G. Pressor and subpressor angiotensin II administration two experimental models of hypertension. AJH. 1995. https://doi. org/10.1016/0895-7061(95)00047-S.

Simone FC. The pharmacology of PEGylation: balancing PD with PK to generate novel therapeutics. J Pharm Sci. 2008;97:4167-83.

Speziale R, Montesano C, De Leonibus ML, Bonelli F, Fezzardi P, Beconi MG, et al. Determination of acetyl coenzyme $A$ in human whole blood by ultra-performance liquid chromatography-mass spectrometry. J Chromatogr B. 2017;2018(1083):57-62.

Veronese FM. Peptide and protein PEGylation: a review of problems and solutions. Biomaterials. 2001;22:405-17.

Vijayaraghavan S, Karami A, Aeinehband S, Behbahani H, Grandien A, Nilsson B, et al. Regulated extracellular choline acetyltransferase activity — the plausible missing link of the distant action of acetylcholine in the cholinergic anti-inflammatory pathway. Silman I, editor. PLoS ONE. 2013;8(6):e65936.

Whelton PK, Carey RM, Aronow WS, Casey DE, Collins KJ, Himmelfarb CD, et al. 2017 ACC/AHA/AAPA/ABC/ACPM/AGS/APhA/ASH/ASPC/NMA/PCNA guideline for the prevention, detection, evaluation, and management of high blood pressure in adults a report of the American College of Cardiology/American Heart Association Task Force on Clinical practice guidelines. Hypertension. 2018;71:E13-115.

World Health Organization. A global brief on hypertension-World Health Day 2013. Geneva: World Health Organization; 2013.

Zhou Y, Varadharaj S, Zhao X, Parinandi N, Flavahan NA, Zweier JL. Acetylcholine causes endothelium-dependent contraction of mouse arteries. Am J Physiol Circ Physiol. 2005;289(3):H1027-32.

Zhou D, Xi B, Zhao M, Wang L, Veeranki SP. Uncontrolled hypertension increases risk of all-cause and cardiovascular disease mortality in US adults: the NHANES III Linked Mortality Study. Sci Rep. 2018. https://doi. org/10.1038/s41598-018-27377-2.

\section{Publisher's Note}

Springer Nature remains neutral with regard to jurisdictional claims in published maps and institutional affiliations.

Ready to submit your research? Choose BMC and benefit from

- fast, convenient online submission

- thorough peer review by experienced researchers in your field

- rapid publication on acceptance

- support for research data, including large and complex data types

- gold Open Access which fosters wider collaboration and increased citations

- maximum visibility for your research: over $100 \mathrm{M}$ website views per year

At BMC, research is always in progress.

Learn more biomedcentral.com/submissions 